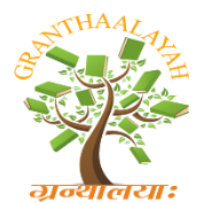

\author{
INTERNATIONAL JOURNAL OF RE
GRANTHAALAYAH \\ A knowledge Repository
}

Science

\title{
PREVALENCE, PATTERN AND DETERMINANTS OF FAST FOOD CONSUMPTION AMONG SCHOOL AGE CHILDREN IN JOS METROPOLIS, PLATEAU STATE, NIGERIA: AN IMPLICATION FOR NUTRITION EDUCATION

\author{
Dr. Ekwuluo Celestine Emeka ${ }^{* 1}$, Dr. Muhammed S.I ${ }^{2}$ \\ ${ }^{* 1,2}$ Department of Community Medicine, Ahmadu Bello University, Nigeria
}

\begin{abstract}
Motivation/Background: In 2001, non-communicable diseases (NCDs) accounted for 60 percent of 56 million deaths worldwide and $47 \%$ of global burden of disease. In all countries, evidence suggested underlying determinants of NCDs were largely same. These include increased consumption of rapidly processed energy-dense nutrient-poor foods high in fat, sugar, salt and reduced levels of physical activity. The objective of this study was to determine prevalence, pattern and determinants of fast foods consumption among school age children in Jos metropolis.

Method: In this study, we used descriptive cross-sectional study and included 347 mothers or care givers with children age 6 to 12 years in our sample size. We applied structured intervieweradministered questionnaire during data collection and analyzed the data with SPSS version 21.0. Results: Prevalence of fast food consumption among school age children in Jos metropolis in the last one week is $91.1 \%$. Knowledge of health risk associated with fast food consumption was $86.5 \%$. Flour based fast food were most commonly consumed. We established an association between meal skipping, fast food advertisement and fast food consumption.

Conclusions: We recommend the need to focus public enlightenment on health risk associated with fast food consumption among school age children. Likewise, children should be encouraged to carry home-made food to school and legislation on fast food advertisement directed at children should be enacted.
\end{abstract}

Keywords: Non-Communicable Disease; Fast Food; Disability Adjusted Life Years; Low and Middle-Income Countries.

Cite This Article: Dr. Ekwuluo Celestine Emeka, and Dr. Muhammed S.I. (2020). "PREVALENCE, PATTERN AND DETERMINANTS OF FAST FOOD CONSUMPTION AMONG SCHOOL AGE CHILDREN IN JOS METROPOLIS, PLATEAU STATE, NIGERIA: AN IMPLICATION FOR NUTRITION EDUCATION." International Journal of Research - Granthaalayah, 8(3), 257-265. https://doi.org/10.29121/granthaalayah.v8.i3.2020.151. 


\section{Introduction}

Good food means the right kind of food for good health, ${ }^{1}$ and it is nutritious. It contains natural substances that the body needs to grow properly and stay healthy. Since socioeconomic conditions and cultural norms of our community have been changing, food habits of our children are also changing. ${ }^{1}$ Many children are fond of ready-made outside food otherwise known as fast food. Fast food is energy dense food with high sugar, fat, salt content and low nutrient value in terms of protein, vitamin and mineral content. ${ }^{2}$

Up till now, many middle and low-income countries are battling with the impact of Noncommunicable diseases (NCDs). ${ }^{3}$ The relationship between unhealthy diet and NCD is well established and there is gradual but persistent shift from communicable disease to NCDs in developing countries. According to the World Health Organization fact report, NCDs kill 40 million people each year, equivalent to $70 \%$ of all deaths globally. ${ }^{3}$ Each year, NCDs result in the death of 15 million people aged between 30 and 69 years and over $80 \%$ of these premature deaths occur in low- and middle-income countries. ${ }^{4}$ Cardiovascular diseases account for most NCD deaths or 17.7 million people annually, unhealthy diet (4.1 million annual deaths have been attributed to excess salt/sodium intake and diabetes). ${ }^{4}$ Although these diseases have led to changes in life pattern and an increase in the disability lost years (DALYs) in the adult population, little or nothing is done to ensure that the young population is protected from having these diseases. ${ }^{4}$ Conversely, Heads of State and Government committed to develop ambitious national responses by 2030 to reduce by one-third premature mortality from NCDs through prevention and treatment (Sustainable development goal 3.4) ${ }^{2}$. This approach of promoting good nutrition and preventing NCD align with the components of primary health care as outlined in Alma Ata in 1978. Surprisingly, little or nothing has been done to ensure that children population especially those in urban places are thought the dangers of unhealthy diets especially the fast food. There has been an outcry for a greater research into the causes of non-communicable disease in the middle and lowincome countries following a gradual but persistent increase in the cases of NCDs in the young population. In sub-Saharan Africa, NCDs contribute a third of the disability-adjusted life year burden, ${ }^{5}$ and kill at a younger age in low- and middle-income countries ${ }^{6}$. Since the deleterious effect of NCDs in low- and middle-income countries can no longer be ignored, ${ }^{7}$ then comes the dire need to carry out a study which will brings to light the prevalence, pattern and determinants of fast food consumption in the school age children whose population has not benefited from any published research on the subject area in this region. Through this study, an insight was gained in the fast food eating pattern of school age children, bring to prominence factors leading to high rate of fast food consumption in the study age group. Accordingly, the upmost benefit of this study is that it provided direct feedback to the participant the risk between non-communicable disease and fast food consumption. Furthermore, it underscored the importance to scale-up nutrition education through behavioral change communication and social marketing, hence ensuring a positive change in attitude and reduced fast food consumption in school age children.

\subsection{Aims}

To determine the prevalence, pattern and determinants of fast foods consumption among school age children in Jos metropolis 


\subsection{Specific Objectives}

1) To ascertain the prevalence of fast food consumption among school age children in Jos metropolis

2) To establish the determinants of fast food consumption among school age children in Jos metropolis

3) To identify the pattern of fast food consumption among school age children in Jos metropolis

4) To assess the knowledge of health risks associated with fast food consumption among school age children in Jos metropolis

\section{Materials and Methods}

\subsection{Study Area, Methods and Material}

The study was conducted in Jos metropolis consisting of Jos North and South Local Government Areas of Plateau state which has an estimated population of 986,648. The study employed a descriptive cross-sectional study and using the statistical method of Leslie-Kish, 359 respondents were sampled. Sampling method was multi-stage random sampling involving four stages as follows;

Stage 1 (Selection of wards). Out of 26 wards in Jos metropolis, 20 wards were selected using random number generator.

Stage 2 (Selection of settlement within a ward): Out of the 26 wards in Jos metropolis, one settlement was selected from each of the selected wards, by balloting.

Stage 3 (Selection of houses and households within a settlement): On arrival at a selected settlement, the first house to be visited was selected from among the houses by balloting. In the selected house, all households were identified. A household was taken as a group of people that ate from the same pot. Where there was more than one eligible household in a house, one of them was selected for interview using balloting.

Stage 4 (Selection of respondent within a selected household): the eligible woman or caregiver (a woman or care giver with a child aged between 6-12 years) within each selected household was identified and interviewed. Where there was more than one eligible woman or care giver, one was selected by balloting and interviewed. Where there was no eligible woman or care giver in a house or on completion of the interview in one household, the interviewer exited that house, moved to the house whose entrance was closest to the right. On reaching the end of the street/path; the street/path to the right and the first house to the right was taken next. This process continued until the required sample size for each settlement was reached.

\subsection{Data Collection and Management}

Data was collected using a structured interviewer-administered questionnaire (Appendix I). The questionnaire was designed in English and had five sessions including section A, sociodemographic characteristics, Section B: Knowledge of health risks associated with fast food consumption. Section C: Prevalence of fast food consumption; Section D: Pattern of fast food consumption and Section E: Determinants of fast food consumption. The questionnaire was adapted from the Study of Consumption, behavior and awareness of fast food among University 
Hostlers $^{8}$ published in the Asian Journal of medicine, and a study on overweight and obesity among school-going children of Lucknow city ${ }^{9}$ published in the Journal of family and community medicine and another study on pattern of fast foods consumption and contribution to Nutrient intake of Nigerian university students, ${ }^{10}$ published in the international journal of education and research. The questionnaire was pretested in a settlement similar to study settlements but located in a different ward. Relevant adjustments were made to the questionnaire based on the observations during the pretest. The questionnaire was scripted and uploaded on Open data kit webpage (https://kf.kobotoolbox.org) and administered using android devices. Data collection was done by a team of four; the researcher and three trained research assistants over three days.

\subsection{Data Analysis}

Data was analyzed using SPSS version 21.0 and was expressed using descriptive statistics including frequencies, percentages and tables. These approaches were employed to describe the socio-demographic factors and economic characteristics of respondents and to examine the determinants of fast food consumption. Continuous variables were described using means and standard deviations (S.D) while categorical variables using frequencies and percentages. Knowledge of health risks association with fast food consumption was assessed and described using percentages and frequencies. Chi-square was used to explore associations between variables of interest e.g. socio-demographic factors and prevalence of fast food consumption. A p value less than 0.05 was considered statistically significant.

\section{Results and Discussions}

The data presented is based on the response of 347 respondents. A total of 359 questionnaires were administered, of these, 347 questionnaires were properly completed giving response rate of $96.7 \%$. The ages of respondents were between 6 and 12 years old. Mean age of respondents in years was $9.1+/-1.7$ SD. Fathers of most respondents had secondary school attendance as the highest level of education. Clerical work, shop owners and farmers made up the largest group of the respondent's fathers' occupation. From the aggregate result, the prevalence of fast food consumption is $91.1 \%$. Socio-demographics are detailed in table 1.

Table 1: Socio-demographics

\begin{tabular}{|l|c|c|}
\hline Variables & Frequency & Percentage (\%) \\
\hline Age of child in years & & \\
\hline 6 & 28 & 8.1 \\
\hline 7 & 33 & 9.5 \\
\hline 8 & 62 & 17.9 \\
\hline 9 & 82 & 23.6 \\
\hline 10 & 59 & 17 \\
\hline 11 & 35 & 10.1 \\
\hline 12 & 48 & 13.5 \\
\hline Gender of Child & & \\
\hline Male & 209 & 60.2 \\
\hline Female & 138 & 39.8 \\
\hline
\end{tabular}




\begin{tabular}{|l|c|c|}
\hline Father's highest level of education & & \\
\hline Didn't attend any school & 8 & 2.3 \\
\hline Primary school & 36 & 10.4 \\
\hline secondary school & 221 & 63.7 \\
\hline Graduate & 75 & 21.6 \\
\hline Post graduate & 7 & 2 \\
\hline Father's Occupation & & \\
\hline Clerical, shop owner, farmer & 167 & 48.1 \\
\hline Unskilled & 11 & 3.2 \\
\hline Semi-skilled & 27 & 8 \\
\hline Skilled & 65 & 18.7 \\
\hline semi professional & 59 & 17 \\
\hline Professional & 18 & 5.2 \\
\hline
\end{tabular}

In table 2, we assessed the knowledge of health risks associated fast food consumption in the study. From the aggregate result (table 2), majority (75.5\%) of respondents acknowledged that heart diseases are linked with fast food consumption. 70.6\% know that Fruits and home prepared food is best for health and $61.4 \%$ that frequent fast food eating makes a person overweight.

Table 2: Respondents Knowledge of Health risks (NCDs) associated with fast food consumption

\begin{tabular}{|l|c|c|}
\hline Variables & Frequency & Percent \\
\hline Heart disease are linked with fast food consumption & 262 & 75.5 \\
\hline Fast food is not a good alternative to healthy food & 109 & 31.4 \\
\hline Fruits and home prepared food are best for health & 245 & 70.6 \\
\hline Frequent fast food eating makes a person overweight & 213 & 61.4 \\
\hline $\begin{array}{l}\text { Fast food eating habit changes ones' attitude towards normal balanced } \\
\text { diet }\end{array}$ & 258 & 74.4 \\
\hline
\end{tabular}

Thereafter, we analysed the data in table $1 \& 2$ above by cross tabulation to explore association between knowledge of health risk connected with fast food consumption and respondents' level of education. The analysis (table 3) established that children whose fathers attended either attended high school, had a first-degree university certificate or postgraduate training are more likely to know the health risk connected with fast food consumption. Similarly, there is strong association between father's profession and knowledge of health risk connected with fast food consumption. However, this did not translate into reduced consumption of fast food among these groups as children whose fathers were professionals, with high level of education were more likely to consume fast food (table 4). The result also did not establish an association between age and gender with fast food consumption.

Table 3: Determinants of Knowledge of Health risks connected with fast food

\begin{tabular}{|l|c|c|c|}
\hline \multicolumn{3}{|c|}{ Knowledge of Health risk connected with fast Food } & \\
\hline Socio-demographics & Good & Poor & Chi-square \\
\hline AGE & & & (P-value) \\
\hline 6 & $24(85.7)$ & $4(14.3)$ & 2.215 \\
\hline 7 & $28(84.8)$ & $5(15.2)$ & 0.899 \\
\hline
\end{tabular}


DOI: 10.5281/zenodo.3734316

\begin{tabular}{|l|c|c|c|}
\hline 8 & $54(87.1)$ & $8(12.9)$ & \\
\hline 9 & $70(85.4)$ & $12(14.6)$ & \\
\hline 10 & $50(84.7)$ & $9(15.3)$ & \\
\hline 12 & $33(94.3)$ & $2(5.7)$ & \\
\hline SEX & $41(85.4)$ & $7(14.6)$ & \\
\hline Male & & & \\
\hline Female & $184(88)$ & $25(12)$ & 1.125 \\
\hline Father's highest-level education & $116(84.1)$ & $22(15.9)$ & 0.289 \\
\hline Didn't attend any school & $3(37.5)$ & $5(62.5)$ & 37.1 \\
\hline Graduate & $71(94.7)$ & $4(5.3)$ & 0.00 \\
\hline High School & $197(89.1)$ & $24(10.9)$ & \\
\hline Postgraduate & $6(85.7)$ & $1(14.3)$ & \\
\hline Primary & $23(63.9)$ & $13(36.1)$ & \\
\hline Fathers occupation & & & \\
\hline Clerical, shop owner, farmer & $155(92.8)$ & $12(7.2)$ & 37.9 \\
\hline Professional & $15(83.3)$ & $3(16.7)$ & 0.00 \\
\hline Semi professional & $56(94.9)$ & $3(5.1)$ & \\
\hline Semi-skilled & $18(66.7)$ & $9(33.3)$ & \\
\hline Skilled & $51(78.5)$ & $14(21.5)$ & \\
\hline Unskilled & $5(45.5)$ & $6(54.5)$ & \\
\hline
\end{tabular}

Furthermore, as seen in table 5, we established strong association between fast food consumption and ease of access to fast food restaurant in school or home as p-value was 0.00 when both variables were cross-tabulated.

Table 4: Determinants of fast food consumption

\begin{tabular}{|l|c|c|c|}
\hline & \multicolumn{2}{|c|}{ Consumed fast food in last one week } & \\
\hline Socio-demographics & No & Yes & (P-value) \\
\hline Age & & & \\
\hline 6 & $2(7.1)$ & $26(92.9)$ & 11.174 \\
\hline 7 & $4(12.1)$ & $29(87.9)$ & 0.083 \\
\hline 8 & $1(1.6)$ & $61(98.4)$ & \\
\hline 9 & $11(13.4$ & $71(86.6)$ & \\
\hline 10 & $6(10.2)$ & $53(89.8)$ & \\
\hline 11 & $1(2.9)$ & $34(97.1)$ & \\
\hline 12 & $6(12.5)$ & $42(87.5)$ & \\
\hline Sex & & & \\
\hline Male & $17(8.1)$ & $192(91.9)$ & 0.413 \\
\hline Female & $14(10.1)$ & $124(89.9)$ & 0.52 \\
\hline Father's highest education level & & & \\
\hline Didn't attend any school & 3 & 5 & 24.172 \\
\hline Graduate & 2 & 73 & 0 \\
\hline High School & 17 & 204 & \\
\hline
\end{tabular}




\begin{tabular}{|l|c|c|c|}
\hline Postgraduate & 0 & 7 & \\
\hline Primary & 9 & 27 & \\
\hline Fathers occupation & & & 15.92 \\
\hline Clerical, shop owner, farmer & 11 & 156 & 0.01 \\
\hline Professional & 0 & 18 & \\
\hline Semi professional & 2 & 57 & \\
\hline Semi-skilled & 4 & 23 & \\
\hline Skilled & 11 & 54 & \\
\hline Unskilled & 3 & 8 & \\
\hline
\end{tabular}

Similarly, frequent meal skipping, easy access to fast food restaurant and frequent viewing of fast food adverts are strongly associated with fast food consumption (table 5). These results align with results of a study carried out by Afolabi et al in 2013 which showed 53.6\% male and 35\% female respondents who skipped meal did consume fast food ${ }^{10}$. Further analysis showed reasons for fast food consumption including respondents who said they can't cook (38.3\%), illness $(22.8 \%)$ and lack of time to cook (19.6\%) are major reasons giving for meal skipping. ${ }^{29}$ Out of the respondents who skipped meal in the last one week, majority (68.9) skipped lunched, this was followed by those who skipped breakfast (15.8\%) and $11.9 \%$ skipped dinner. 33\% of respondents who skipped meal in the last one week, skipped more than a meal per day at home in the last one week. Two main reasons giving by the respondents why they prefer fast food is easy availability $(66.5 \%)$ and easy accessibility 49.1\%. Advertisement influenced fast food consumption by $39.6 \%$ while leisure/socializing did same by $33.2 \%$.

Table 5: Determinants of fast food consumption in last one week

\begin{tabular}{|l|c|c|c|}
\hline \multirow{2}{*}{ Variables } & \multicolumn{3}{|c|}{ Fast food consumption in last one week } \\
\cline { 2 - 4 } & Yes & No & Chi-square (p-value) \\
\hline Meal skipping in last one week & & & \\
\hline Yes & 177 & 0 & 35.443 \\
\hline No & 139 & 31 & 0.00 \\
\hline $\begin{array}{l}\text { Easy access to fast food restaurant at school or } \\
\text { home }\end{array}$ & & & \\
\hline Yes & 206 & 12 & \\
\hline No & 110 & 19 & 8.476 \\
\hline Knowledge of health risk associated with fast food & & & 0.004 \\
\hline Yes & 281 & 19 & \\
\hline No & 35 & 12 & 18.41 \\
\hline Frequent fast food advert viewing & & & 0.00 \\
\hline Yes & 187 & 0 & \\
\hline No & 129 & 31 & 39.786 \\
\hline
\end{tabular}

In this study we found that more than half of the respondents $61.7 \%$ (193) who consume fast food replace their diet with fast food between four and six times in a week. (table 6). This align with the 5 days when school children are mostly away from home. Most compelling evidence shows that fast food consumption habit increased in $76.3 \%$ of the respondents after they started school. Majority (38.6\%) of the respondents preferred consuming fast food in the afternoon, followed by 
$37.7 \%$ of the respondents who do not have any time preference for fast food consumption. It will be pertinent to note that the slightly higher percentage of fast food consumption in the afternoon explains the coping mechanism instituted by the children and their parents as most of the children and/or the respondents are in school or at their workplaces. This strongly supports the notion that away from home is a strong factor that drives fast food consumption.

Flour based fast food, followed by meat based, then dairy products are the most commonly consumed fast food. Alcohol accounted least with a percent of 0.3 (1) respondent which was followed by fruit juices accounting for $87(27.5 \%)$.

Table 6: Pattern of fast food consumption among respondents who consume fast food

\begin{tabular}{|l|c|c|}
\hline Variables & Frequency & Percentage \\
\hline Fast food consumption in a week & & \\
\hline$<4$ & 52 & 16.5 \\
\hline 4 to 6 & 218 & 69 \\
\hline 7 to 9 & 41 & 13 \\
\hline 10 and above & 5 & 1.6 \\
\hline Types of fast food & 237 & 75 \\
\hline Flour based & 120 & 38 \\
\hline Diary product & 173 & 54.7 \\
\hline Meat based & 87 & 27.5 \\
\hline Fruit juices & 1 & 0.3 \\
\hline Alcohol drinks & 29 & 9.20 \\
\hline Fast food time preference & 119 & 37.7 \\
\hline Morning & 46 & 14.6 \\
\hline Afternoon & 112 & 38.6 \\
\hline Evening & \multicolumn{2}{|c|}{} \\
\hline Anytime & 193 & 61.7 \\
\hline Frequency of replacing homemade food with fast-food in a week \\
\hline$<4$ & 61 & 19.3 \\
\hline 4 to 6 & 11 & 3.5 \\
\hline 7 to 9 & 51 & 16.1 \\
\hline 10 and above & & \\
\hline
\end{tabular}

\section{Conclusion and Recommendation}

Prevalence of fast food consumption and knowledge of health risks connected with fast food consumption is high. Children whose fathers were professionals with high level of education, frequent fast food advert viewing, meal skipping and easy access to fast food restaurant are strongly associated with fast food consumption. Furthermore, Easy accessibility and availability of fast food are the commonest given reason for fast food consumption. Flour based fast foods is the most consumed fast food and more children prefer fast food consumption in the afternoon. The result buttresses the need with to regulate fast food consumption as in-line with the 2015 World health Organization report on the need for regulation of fast food which brought to fore front that living near a fast food restaurant has been linked to a 5.2 percent greater risk of obesity. ${ }^{11}$ 
Similarly, towards achieving the sustainable development goal (SDG 3.4) which highlighted the dire need to reduce by one third premature mortality from non-communicable diseases through prevention and treatment and promote mental health and well-being, Social behavioral change communication and social marketing should be scaled up. This will be geared towards increasing public awareness on health risk of fast food consumption among school age children. Likewise, mandatory nutrition education targeting proper nutrition and links between poor nutrition and diseases should be incorporated into Nigeria primary and junior secondary school curriculum. Parents should be encouraged to carry home-made food with them during outings and encourage their children to carry home-made food to their school. While these are ongoing, legislation on fast food advertisement directed at children should be enacted with the view to curbing excessive fast food advertisement and enforcing regulations on opening of fast food near schools or home.

Low levels of overweight in children.

\section{References}

[1] Jagadish C, D. Fast Food Consumption in Children [internet], 2015. [cited 20th August 2017] Available from: https://www.researchgate.net/publication/282115918_Fast_Food_Consumption_in_Children_A_ Review

[2] 2. Kaushik JS, Narang M, Parakh A. Fast food consumption in children. Indian Pediatrics 2011; (48):95-101.

[3] 3. World Health Organization. 10 facts on Non-communicable diseases [internet] 2017. [cited $24^{\text {th }}$ August 2017]. Available from:

http://www.who.int/features/factfiles/noncommunicable_diseases/facts/en/index.htm

[4] Global burden of diseases. Risk Factors Collaborators. Global, regional, and national comparative risk assessment of 79 behavioral, environmental and occupational, and metabolic risks or clusters of risks, 1990-2015: a systematic analysis for the Global Burden of Disease Study 2015. Lancet, 2016; 388(10053):1659-1724

[5] Beaglehole R, Ebrahim S, Reddy S, et al. Prevention of chronic diseases: a call to action. Lancet 2007; (307) 2152-2157.

[6] Alan, A. et al WHO Global status report on non-communicable diseases [internet] 2010. [cited August $24^{\text {th }}$, 2017]. Available from: http://www.who.int/nmh/publications/ncd_report_full_en.pdf

[7] Ebrahim S, Smeeth L. Non-communicable diseases in low and middle-income countries: a priority or a distraction? International Journal of Epidemiology. 2005; 34:961-966. [PubMed: 16150869]

[8] Study of Consumption, behavior and awareness of fast food among University Hostlers. Asian Journal of Clinical medicine 2013; Vol. 5 (1): 1 -7.

[9] Vohra R, Bhardwaj P, Srivastava JP, Srivastava S, Vohra A. Overweight and obesity among schoolgoing children of Lucknow city. Journal of Family and Community Medicine 2011.18:59-62

[10] Afolabi, W, A. Towobola, S.K. Oguntona, C.R. and Olayiwola I,O. Pattern of fast foods consumption and contribution to Nutrient intake of Nigerian university students. International journal of education and research 2013; 1 (5).

[11] Smorlaski, M. World Health Organization. Study Proves need for regulation of fast food industries [internet], 2015. [cited 22 ${ }^{\text {nd }}$ August 2017] Available from https://foodtank.com/news/2015/08/

*Corresponding author.

E-mail address: celesmeka@yahoo.com 